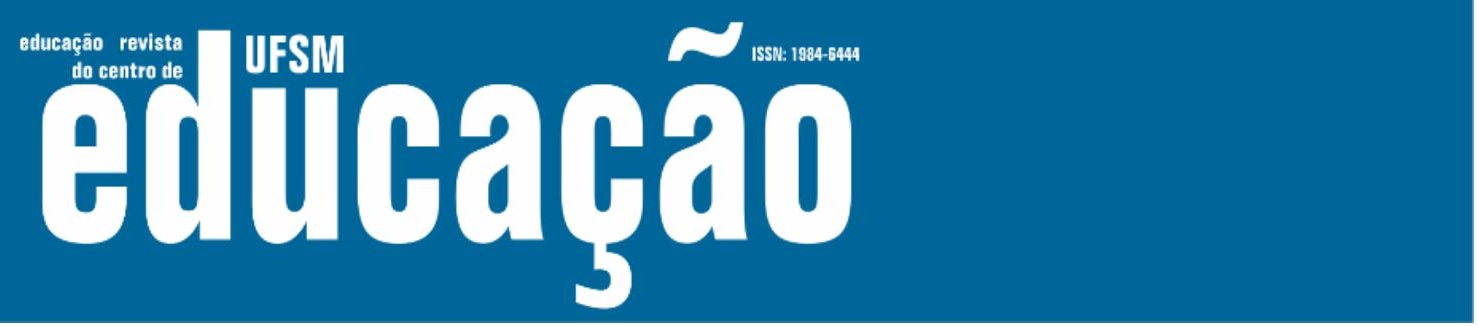

ISSN: 1984-6444 | http://dx.doi.org/10.5902/1984644445306

\title{
Igualdade é uma palavra que o sonho humano alimenta: Rancière e a crítica aos discursos pedagógicos contemporâneos $^{1}$
}

Equality - a word nourished by human dreams: Rancière's criticism on contemporary pedagogical discourses

José Sérgio Fonseca de Carvalho

Professor Doutor da Universidade de São Paulo. São Paulo, São Paulo, Brasil.

jsfcusp@usp.br - https://orcid.org/0000-0002-0074-0872

Recebido em 01 de junho de 2020

Aprovado em 15 de setembro de 2020

Publicado em 30 de junho de 2021

\section{RESUMO}

Em O Espírito da Leis, Montesquieu atribui à educação - e, em particular, à sua forma escolar - a tarefa de difundir e cultivar o amor à igualdade, por ele concebido como a virtude política por excelência e como o princípio afetivo que sustenta o regime republicano como modo de vida. O desafio que sua obra lança aos educadores - o de viabilizar uma educação comprometida com o amor à igualdade mobiliza os discursos educacionais republicanos que, desde então, procuraram conceber meios de efetivar o princípio da igualdade no âmbito das instituições educativas. O presente artigo analisa diferentes formas pelas quais os discursos educacionais se propuseram a operacionalizar esse princípio no plano das relações educativas. Partimos da análise da escola pública como esforço de efetivação do princípio liberal da igualdade de oportunidades e apresentamos, a seguir, as críticas a ela endereçadas pelas teorias reprodutivistas e pelas correntes pedagógicas autoproclamadas histórico-críticas. Em um terceiro momento, buscamos articular as críticas de Jacques Rancière a ambas as correntes, apresentando uma perspectiva na qual o compromisso com a igualdade não é concebido como um objetivo da ação educativa a ser alcançado no futuro, mas como um axioma capaz de produzir efeitos igualitários em suas ações presentes.

Palavras-chave: Filosofia da Educação; Igualdade; Jacques Rancière. 


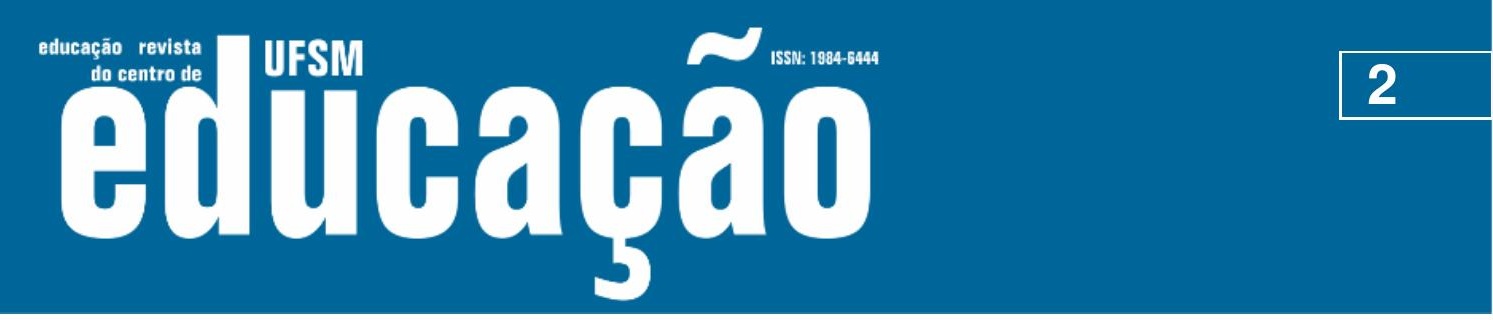

ISSN: 1984-6444 | http://dx.doi.org/10.5902/1984644445306

\section{ABSTRACT}

In The Spirit of the Laws, Montesquieu attributes to education - and, in particular, to school form - the task of spreading and cultivating the love for equality, conceived as the political virtue par excellence and as the principle that supports the republican regime as a way of life. The challenge that his work poses to educators - that of an education system committed to making equality viable - mobilizes republican educational discourses which, since then, have tried to devise ways to implement the principle of equality within educational institutions. This article analyzes different ways by which educational discourses have proposed to operationalize this principle in terms of educational relationships. We start from the analysis of the public school as an effort to implement the liberal principle of equal opportunities, followed by the criticisms addressed to it by the reproductive theories and by the historical-critical pedagogical movement. In a third moment, we seek to articulate Rancière's criticisms to both currents, as he presents a perspective in which the commitment to equality is not conceived as an objective of the educational action to be reached in the future, but as an axiom capable of producing egalitarian effects in present actions.

Keywords: Philosophy of Education; Equality; Jacques Rancière.

\section{Um marco fundador: o amor à igualdade como princípio da educação republicana}

No prefácio da segunda edição de O espírito das Leis, Montesquieu (1996) adverte seu leitor quanto ao sentido peculiar que confere ao termo virtude em suas reflexões acerca das relações entre política e educação. Não se trata, esclarece o autor, de uma virtude moral - nem cristã -, mas sim de uma virtude especificamente política: o amor à igualdade. Ela se relaciona antes com os vínculos que unem os cidadãos entre si e com o regime de governo em que vivem do que com escolhas subjetivas e pessoais. Essa virtude - o amor à igualdade - é o princípio que anima o regime republicano como modo de vida. Paralelamente à sua estrutura jurídica e política, todo e qualquer regime de governo implementa e cultiva um princípio que opera como elemento afetivo propulsor das ações dos súditos ou cidadãos, pois, para Montesquieu, "nenhuma forma de governo subsiste se faltar a paixão que lhe serve de suporte" (RIBEIRO, 1996, p. XX). Daí a importância que o pensador francês atribuirá à educação, tema do qual se ocupará já nas primeiras seções de 


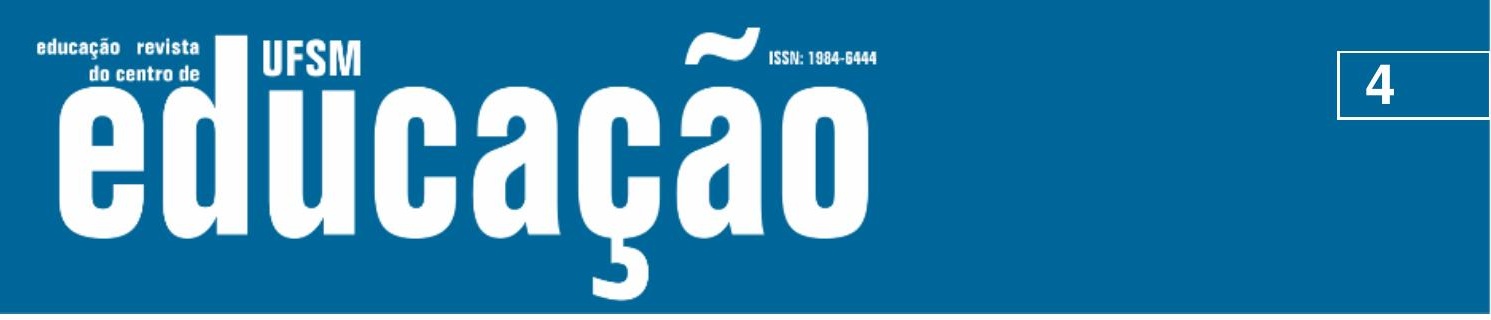

ISSN: 1984-6444 | http://dx.doi.org/10.5902/1984644445306

regimes despóticos: "E por que [no despotismo] a educação se esforçaria para formar um bom cidadão? Ora, se ele amasse ao Estado ficaria tentado a sabotar o governo" (MONTESQUIEU, 1996, p. 45).

Ao contrário, no governo republicano a educação - particularmente em sua forma pública e institucional, a escola - torna-se um dispositivo crucial:

É no governo republicano que se precisa de todo o poder da educação. O
temor dos governos despóticos nasce espontaneamente entre as ameaças
e os castigos; a honra das monarquias é favorecida pelas paixões e as
favorece, por sua vez; mas a virtude política é uma renúncia a si mesmo,
que é sempre algo muito difícil ...[porque] exige que se prefira
continuamente o interesse público ao seu próprio interesse.
(MONTESQUIEU, 1996, p.46).

Assim, mais do que uma competente iniciação em saberes e conhecimentos, a educação republicana deve almejar, para Montesquieu, a transmissão intergeracional de um afeto: o amor à igualdade. E, lembra-nos o autor: "se temos o poder de transmitir nossos conhecimentos a nossos filhos; temos o poder ainda maior de transmitir-lhes nossas paixões" (MONTESQUIEU, 1996, p. 46). Entre elas, a paixão pela igualdade, princípio afetivo que vincula cada cidadão a uma comunidade política na qual se insere e da qual participa; uma paixão que a vida republicana fomenta e que, por sua vez, Ihe renova o vigor.

É sobremaneira difícil, mesmo em um pensador político tido por realista como Montesquieu, operar com precisão um recorte entre o que é um esforço de compreensão do real e o que pode ser uma proposição programática; entre o que pode ser descrito como o "espaço em que a vocação é do cientista e outro em que ela é do político" (RIBEIRO, 1996, p. XXXV). Felizmente para aqueles, como nós, que nele buscamos subsídios para o pensamento e a ação educacional, essa cisão se torna, em grande medida, ociosa. Ao vincular a educação republicana ao amor à igualdade, Montesquieu lança a todos aqueles que se ocupam da educação um desafio simultaneamente teórico e prático; reflexivo e programático. As relações entre educação e igualdade tornaram-se, desde então, um problema ao qual professores, pedagogos, políticos, sociólogos e filósofos têm voltado sua atenção de forma incessante. Dentre outras razões, porque um princípio - por mais consensual 


\section{Eithrapẫ}

ISSN: 1984-6444 | http://dx.doi.org/10.5902/1984644445306

que possa vir a ser em uma sociedade - jamais carrega em si as regras de sua aplicação prática. E as escolhas relativas às formas de sua efetivação sempre estarão sujeitas ao confronto com concepções alternativas que, a despeito de compartilharem o mesmo princípio, nele vislumbram sentidos diversos e dele retiram novas implicações.

\section{A igualdade de oportunidades: horizonte normativo ou dissimulação da dominação?}

Uma primeira - e até hoje bastante influente - forma de operacionalização prática desse princípio republicano foi a idealização da escola como uma instituição potencialmente capaz de materializar a utopia liberal de uma sociedade erigida a partir da igualdade de oportunidades e da valorização dos méritos individuais como fundamentos legítimos para a divisão desigual de riquezas e de prestígio social. Se em sociedades estamentais a hierarquia social deriva diretamente dos laços de sangue, no ideal das democracias liberais modernas ela deveria se fundar em uma competição livre e justa entre indivíduos concebidos como iguais em direitos e liberdades. Uma competição análoga, por exemplo, à lógica das disputas esportivas que se consolidaram a partir das últimas décadas do século XIX. Assim, se as escolas lograssem efetivar o princípio da igualdade de oportunidades, as desigualdades escolares e sociais dela derivadas seriam tão justas quanto as que decorrem de uma competição esportiva na qual há vencedores e perdedores, sem que se coloque em questão a legitimidade do resultado, desde que garantidas a imparcialidade do árbitro e a observância das regras (Cf. DUBET, 2004). O problema residiria, pois, na implementação de políticas públicas de educação que garantissem a universalidade do acesso à escola e a imparcialidade de seus critérios de seleção, de forma que todos pudessem, ao menos em princípio, concorrer em igualdade de condições.

Embora as formulações teóricas e o reconhecimento jurídico do igual direito de todos à educação remontem ao século XIX, foi somente na segunda metade do século XX que um número significativo de países conseguiu romper com a dicotomia 


\section{Autตaดูão}

ISSN: 1984-6444 | http://dx.doi.org/10.5902/1984644445306

que destinava a escola elementar aos filhos de trabalhadores e o ensino secundário às elites econômicas e culturais. A universalização das oportunidades escolares tornou-se objeto de uma luta que ultrapassou largamente o escopo do pensamento liberal. Na França, a reforma Langevin-Wallon, conduzida por intelectuais vinculados ao pensamento marxista, pregava a expansão da oferta de escolarização para as classes trabalhadoras como uma forma de fomento à igualdade. No Brasil, a defesa da escola pública nos anos cinquenta congregou intelectuais de posições tão diversas quanto Florestan Fernandes e Roque Spencer M. de Barros. Como destaca Dubet (2004, p. 36, tradução nossa), o princípio da igualdade de oportunidades deixou, assim, de ser apenas "um avatar da ideologia liberal e burguesa para se tornar uma concepção fundamental de justiça em uma sociedade democrática composta de indivíduos a priori iguais entre si".

O ideal de universalização do acesso à educação básica, embora até agora não plenamente logrado, conheceu êxitos significativos desde então. No caso brasileiro, a eliminação da barreira de acesso aos estudos secundários - iniciada no final da década de sessenta e generalizada ao longo das seguintes - implicou uma transformação substancial nas práticas escolares e nos debates acerca da educação. Mas, não obstante os inegáveis méritos da abertura da escola a segmentos da população que a ela jamais haviam tido acesso, a medida frustrou a expectativa de concretização de uma igualdade de oportunidades. A cisão, cristalizada desde então, entre os sistemas público e privado de educação realocou o privilégio dos privilegiados em novas bases, de forma que o acesso aos cursos superiores de maior prestígio social e retorno econômico permaneceu sendo um privilégio das elites oriundas das escolas privadas. Mas mesmo em países nos quais o sistema público de educação é hegemônico, como no caso da França, a esperança transformou-se em desilusão. Em que pese o aumento significativo da escolarização da população como um todo, operou-se uma espécie de democratização seletiva, tanto por conta de fatores externos à escola - como a concentração das melhores escolas em bairros privilegiados - como por fatores internos, uma vez que as práticas escolares tendem a privilegiar alunos e alunas cujos hábitos culturais familiares estão mais próximos de seus valores e expectativas 


\section{Althaห̧ão}

ISSN: 1984-6444 | http://dx.doi.org/10.5902/1984644445306

irão abordar o problema das relações entre educação e igualdade a partir de uma nova ótica, de cunho macroestrutural. Em que pese a ampla variedade de perspectivas geralmente identificadas como reprodutivistas, parece haver entre elas ao menos um traço em comum: a explicitação das formas pelas quais as relações de poder exterior à escola - sejam elas de cunho cultural ou econômico - condicionam escolhas curriculares, normas de funcionamento e mecanismos de seleção escolar, sempre de forma a privilegiar os segmentos já privilegiados da sociedade e, ao mesmo tempo, legitimar e ocultar esse processo de reprodução das desigualdades sociais. A força argumentativa dessas investigações desferiu um duro golpe no ideal da igualdade de oportunidades, que desde então tem sido muitas vezes visto menos como um horizonte normativo de justiça do que como um ardil retórico e ideológico comprometido com a legitimação e a dissimulação do papel da escola na produção e reprodução das desigualdades de classe que marcam a sociedade capitalista.

\section{As apropriações pedagógicas das teorias reprodutivistas}

O impacto das teorias reprodutivistas no campo da educação - mais ligado à sua divulgação por comentadores do que à leitura das investigações originais - não deve ser subestimado. Entre professores, sua difusão gerou muitas vezes um ceticismo paralisante. A transmutação de uma regularidade estatística, construída a partir de um contexto específico, em uma verdade pretensamente universal transformou o que era uma correlação condicional em causalidade determinista. E, nessa operação, acabou por transformar o pertencimento a um segmento social em signo indicador de um destino escolar inexorável: a reprovação e o fracasso. A naturalização do fracasso escolar migrou, então, da ideologia do dom pessoal para a ideologia do capital cultural.

Foi em grande medida em resposta a essa tendência, cética em relação ao papel da escola na promoção da igualdade, que um conjunto expressivo de teóricos e intelectuais da educação procurou tecer novas formas de enfrentar o desafio de vincular a ação educativa ao princípio da igualdade, sem ignorar a contribuição dessas teorias sociológicas. Em um texto paradigmático desse movimento, 


\section{Authaดูã}

ISSN: 1984-6444 | http://dx.doi.org/10.5902/1984644445306

suposições e práticas que informam as experiências vividas na escolarização cotidiana", de forma a "revelar a distinção entre a realidade e as condições que escondem a realidade" (GIROUX, 1997, p. 39-41).

Ora, em que pese a radical diferença nos pressupostos teóricos, é notável a semelhança entre a proposta de Giroux e a icônica imagem a que Platão (2000, Livro VII) recorre para veicular a tarefa educativa do filósofo: emancipar os habitantes da caverna por meio de uma ortopedia do olhar (BRAYNER, 2018) cuja função seria precisamente a superação da ilusão, desvelando um suposto simulacro que se interporia entre o sujeito e o real. Em ambos os casos, trata-se de propor uma gradativa apropriação do real que, pedagogicamente orientada, garantirá o processo emancipatório e sua promessa de justiça e igualdade como objetivos a serem alcançados ao final de uma longa jornada. Uma igualdade geométrica em Platão; que se transmutará em uma igualdade de oportunidades no projeto liberal republicano e, finalmente, resultará na reformulação pedagógica e curricular visando ao desvelamento da ideologia e à superação das desigualdades sociais nas pedagogias histórico-críticas. $\mathrm{Na}$ verdade, em todos esses casos, igualdade e emancipação são tomadas como objetivos da ação educativa. Uma ação cuidadosamente planejada e prevista por aqueles que se concebem como detentores de um saber acerca do real - e de um saber acerca de suas formas de transmissão - que permanece oculto aos olhos dos leigos. E será em clara contraposição a esses dois pressupostos que Jacques Rancière tecerá uma crítica radical dos discursos políticos e pedagógicos que evocam a emancipação e a igualdade como uma promessa dos que sabem aos que ignoram.

\section{Rancière: a igualdade como ponto de partida do caminhar}

A ruptura que Rancière opera no debate já se inicia com a forma pela qual tece seu ponto de vista em relação às tendências dominantes nas discussões sobre as relações entre educação, igualdade e emancipação. Sua obra $O$ mestre ignorante (1987) não corresponde a qualquer classificação acadêmica corriqueira: trata-se de uma narrativa de um evento do século XIX, permeada por questões filosóficas, 


\section{OFEM H Eutinará}

ISSN: 1984-6444 | http://dx.doi.org/10.5902/1984644445306

políticas e educacionais que dialogam com os debates que marcam a segunda metade do século $X X$, sem a eles fazer referências diretas. Jacotot - seu personagem central - é um revolucionário francês exilado nos países baixos, a quem foi confiado um posto na Universidade da Lovaina. Lá ele se depara com um desafio inusitado: ensinar francês a alunos que falam neerlandês, sem que ele domine essa língua. Sua ignorância da língua nativa de seus alunos o leva a uma aventura intelectual e pedagógica, à qual responde sugerindo-lhes a leitura de uma edição bilingue da obra As Aventuras de Telêmaco, de Fenelon. Como não conhecia a língua de seus alunos, Jacotot nada podia lhes transmitir além de um desafio intelectual: eles deveriam enfrentar por si sós, com o recurso de suas próprias inteligências e sem a interferência e a explicação de um mestre, o desafio de compreender uma obra, de interpretar seu sentido e ser capaz de sobre ela falar e escrever.

O entusiasmo com que os alunos acolheram sua proposta e o resultado exitoso dessa experiência levaram Jacotot a pôr em questão a própria estrutura que preside a relação pedagógica: a noção de que cabe ao professor explicar a matéria - ou objeto de estudos - a seus alunos a fim de que estes a compreendam e, assim, caminhem gradativamente em direção à superação da desigualdade que marca os lugares de aluno e de professor. Mas, pergunta Jacotot, seria a explicação - a sequência de atos mediadores visando "dispor os elementos do saber a ser transmitido a partir de seu suposto acordo com as capacidades alegadamente limitadas das mentes ainda não instruídas" (RANCIÈRE, 2002, tradução nossa) realmente um passo em direção à igualdade? Ou, na verdade, o ato de explicar seria, antes, a expressão da própria crença na desigualdade como constituinte da relação pedagógica? Explicar algo a alguém não implicaria sugerir que, sem a explicação de um mestre que detém saberes, informações e verdades ocultas àqueles a quem ele ensina, estes seriam incapazes de aprender? $O$ ato de explicar não expressaria a convicção de que, sem o olhar iluminado de um professor que detém a ciência e desvela os ardis da ideologia, os alunos estariam fadados a permanecerem na caverna das ilusões? E, sobretudo, a prática explicativa não implicaria serem os mestres não somente detentores do conhecimento, mas também 


\section{Aitlnaดูão}

ISSN: 1984-6444 | http://dx.doi.org/10.5902/1984644445306

dos saberes necessários à sua transmissão, ou seja, serem detentores de um saber acerca da ignorância do outro?

Ora, para Jacotot, a pedagogia da explicação e seus pressupostos fundantes - a desigualdade como ponto de partida e a igualdade como objetivo - prometem a emancipação, mas promovem o embrutecimento. Isso porque, ao projetar a igualdade para um futuro - sempre adiado, sempre um pouco além... -, essas práticas pedagógicas acabam por negá-la como axioma que potencializa ações capazes de atestá-la no presente. Quando propôs a seus alunos uma aventura intelectual, que deles exigia um caminho próprio no aprendizado da língua francesa, Jacotot apostou menos em qualquer sistema pedagógico do que em uma convicção política que marca sua trajetória como homem público e como professor: a crença na igualdade das inteligências. Trata-se, de forma sucinta, da convicção de que todo e qualquer ser humano é igualmente capaz de compreender e traduzir para si - ou reconfigurar e ressignificar - qualquer obra criada por outra inteligência humana; uma inteligência que não é superior, nem inferior à sua. Não se trata, para Jacotot, de relativizar e equalizar as diferentes manifestações de uma capacidade comum, mas antes de distinguir a capacidade compartilhada das formas específicas e singulares em que ela se manifesta.

A igualdade das inteligências não é, pois, tomada por Jacotot como um fato empírico, mas como um axioma inicial - um princípio gerador de ações - que reflete uma convicção política. A adoção desse axioma nada tem a ver com um questionamento acerca, por exemplo, da fidedignidade de pesquisas empíricas ou de testes psicométricos. Ele representa, antes, um significativo deslocamento conceitual. O que um teste de QI, voltado para a mensuração do desempenho específico de um indivíduo em provas de raciocínio lógico-matemático, mede? A inteligência ou a mera manifestação pontual e circunstancial de uma capacidade comum que se manifesta em todo e qualquer ato de criação de uma obra humana, seja ela a fabricação de uma luva, a tessitura de uma obra literária ou a resolução de uma equação?

Mas a crítica de Jacotot é ainda mais profunda do que o exemplo acima sugerido. Trata-se de pôr em questão qualquer forma de atestação empírica da 


\section{Autharão}

ISSN: 1984-6444 | http://dx.doi.org/10.5902/1984644445306

igualdade - ou de seu contrário, a desigualdade - como um fato passível de mensuração para concebê-la, antes, como uma potência capaz de se atualizar na concretude de um gesto presente. Esse deslocamento conceitual transforma as noções de igualdade e desigualdade em elementos operativos do discurso e da ação política. Elementos que não se deixam apreender por reduções a dados estatísticos ou a mensurações psicométricas. É nesse sentido que Rancière (2003, p. 71, tradução nossa) nos adverte que "liberdade e igualdade são potências que se engendram e crescem por um ato que Ihes é próprio". Não se pode, pois, falar de uma liberdade ou de uma igualdade ilusória. Elas devem, antes, ser concebidas como potências "em relação às quais convém verificar os efeitos" (RANCIĖRE, 2003, p. 71, tradução nossa) por meio de atos que a fazem eclodir e vir à tona.

Assim, afirmar que somos seres livres não implica asseverar um fato, mas apenas atestar que, ao agir - ao romper com qualquer sorte de determinação ou de amarras do passado sobre o presente -, nós verificamos a existência da liberdade como potência sempre presente de fazer eclodir o novo, o inesperado, o imprevisível (ARENDT, 1996). Não somos, pois, livres antes do ato, nem conquistamos a liberdade como resultado do ato. É no próprio ato - e somente nele - que a liberdade se manifesta como uma realização concreta e presente. Somos livres ao agir livremente porque verificamos em ato a potência da liberdade. De forma análoga, somos iguais não porque estejamos inseridos em um ordenamento jurídico que enuncia a igualdade, mas porque somos capazes de produzir formas até então inusitadas de verificação da igualdade de todos com qualquer um, nos mais diversos domínios de nossas existências.

Ora, o exercício proposto por Jacotot a seus alunos é precisamente um ato de verificação da igualdade. E ele assim se constitui não porque o conhecimento transmitido pela obra - seu conteúdo pedagógico - tenha a propriedade de gradativamente reduzir a suposta desigualdade entre mestre e alunos, mas porque a experiência de afirmar em ato a igualdade das inteligências - de verificá-la em sua manifestação presente - subverte a ordem hierárquica que comanda 0 ato pedagógico. Não se caminha em direção à igualdade. Ela é, antes, o ponto de partida do caminhar. 


\section{O Hism Althapat

ISSN: 1984-6444 | http://dx.doi.org/10.5902/1984644445306

Assim, verificar o axioma da igualdade implica criar uma forma de torná-lo verídico por um ato que dá a ver - no espaço comum - os efeitos de sua adoção. Noutras palavras, ao tomar a igualdade como um princípio, nós podemos produzir um evento que a testemunhe como capacidade, ainda que em um domínio específico e não totalizador. Trata-se de uma noção que se torna evidente pela mera constatação de que todos nós nos tornamos igualmente dotados da capacidade de falar - de dominar uma linguagem, de participar de um $\operatorname{logos}^{2}$ comum - como decorrência do fato de que nossos pais, irmãos e amigos se dirigiram a cada um de nós, enquanto éramos bebês (na qualidade de infans; de seres ainda não falantes, segundo a língua latina), como se fôssemos falantes dotados da mesma e igual capacidade de todos os demais. É, pois, porque cremos na igualdade como ponto de partida que a atualizamos - que a verificamos, no sentido de torná-la uma verdade tangível - a cada nova experiência do presente. Assim, ao acolher cada infans como um potencial falante, dele fazemos um igual participante de uma comunidade de falantes. Se fôssemos adotar o preceito de nos adaptar aos supostos limites da inteligência do outro - neste caso, o infans -, não nos dirigiríamos a ele com frases e interrogações que o tomam como um igual, mas a partir de balbucios. Não se trata, pois, de uma ilusão, mas de uma aposta: ao incorporar o axioma da igualdade, nós a produzimos. Como afirma Rancière (1987, p. 32, tradução nossa):

No rendimento desigual das diversas aprendizagens intelectuais, o que todos os filhos dos homens aprendem melhor é o que nenhum mestre lhes pode explicar - a língua materna. Fala-se a eles, e fala-se em torno deles. Eles escutam e retêm, imitam e repetem, erram e se corrigem, acertam por acaso e recomeçam por método, e, em idade muito tenra [...] são capazes, quase todos - qualquer que seja seu sexo, condição social e cor de pele de compreender e de falar a língua de seus pais.

É, pois, a partir de uma experiência de igualdade - a igual capacidade de todos a participarem de uma linguagem comum por meio da qual expressamos não só nossas necessidades, mas nossos desejos, juízos e formas de compreensão do mundo - que os filhotes dos humanos se humanizam. E é sobre essa igualdade primeira que se constrói toda e qualquer desigualdade social posterior. Isso porque 


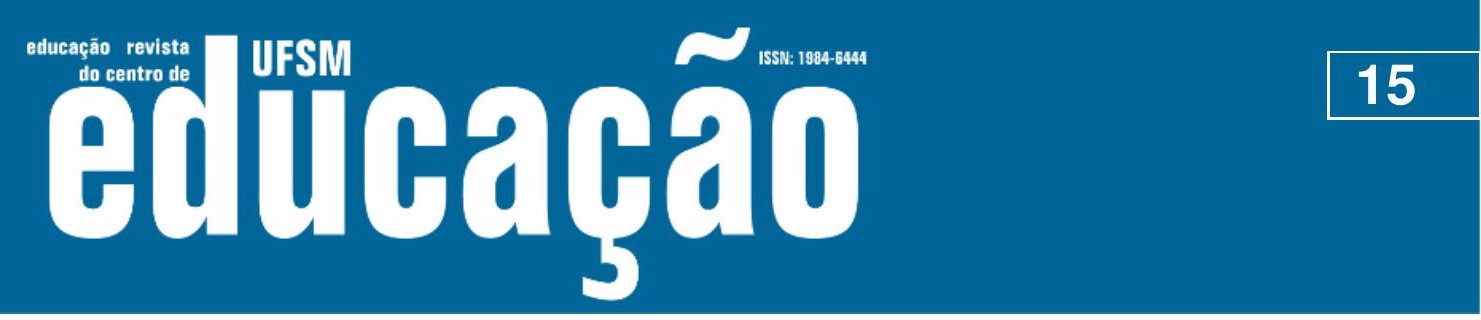

ISSN: 1984-6444 | http://dx.doi.org/10.5902/1984644445306

mesmo aquele que se julga superior deve admitir uma igualdade inicial básica: aqueles a quem considera seus inferiores têm de ser igualmente capazes de dominar a língua e os signos por meio dos quais ele thes comunica sua alegada - e arbitrária - superioridade. Como destaca Rancière (2002, tradução nossa): "há uma igualdade dos seres falantes que antecede a relação de desigualdade, uma relação que cria as próprias condições para a existência de qualquer desigualdade. É isto que Jacotot chama de 'igualdade das inteligências'”. Assim, as diferenças nas manifestações da inteligência simplesmente refletem um maior ou menor empenho na execução da tarefa; uma vontade mais ou menos empenhada em uma atividade determinada, que não deve ser confundida com uma hierarquia de inteligências ou capacidades. Daí porque caberá ao mestre - ou ao professor - agir não sobre a inteligência do aluno que se debruça sobre uma obra, mas sobre sua vontade, a fim de que ele se conceba e atue a partir da convicção de sua igual capacidade de produzir, interpretar e traduzir qualquer obra criada pela inteligência humana.

O deslocamento conceitual operado por Rancière não é, pois, meramente teórico. Dele resulta a proposição de uma perspectiva radicalmente inovadora quanto à natureza do trabalho docente comprometido com uma prática emancipadora e vinculada ao princípio da igualdade. Em primeiro lugar porque os caminhos da emancipação e da igualdade deixam de ser vinculados à comunicação de um saber - o da ciência, no projeto republicano ou o dos ardis da ideologia, nas pedagogias críticas - para se constituir em uma forma de relação com 0 conhecimento e com os que com ele interagem. O que o mestre emancipador transmite não é, pois, um conteúdo supostamente emancipador, mas uma vontade política de emancipar-se: a decisão de romper o círculo da impotência que leva alunos e alunas a crerem no axioma da desigualdade das inteligências. Trata-se, pois, de superar a engrenagem pedagógica que visa justificar o lugar de cada um no ideal de uma sociedade orgânica, tal como a descreve Durkheim (1965).

Mas Rancière mobiliza a reflexão de Jacotot também como crítica a apropriações pedagógicas da sociologia de Bourdieu e Passeron, na medida em que estas recorrem a investigações empíricas a fim de atestar a desigualdade como um fato sociológico acessível somente ao olhar do especialista, capaz de informar e 


\section{Autharão}

ISSN: 1984-6444 | http://dx.doi.org/10.5902/1984644445306

desvelar a seus inferiores - os professores - o verdadeiro sentido de seu exercício profissional: a dissimulação da reprodução social. Cria-se, a partir dessas apropriações, um duplo caminho para a reiteração da desigualdade que se pretende denunciar e combater. Em uma primeira via, cabe aos professores, agora iluminados pelos especialistas, promover reformas nos conteúdos e práticas escolares a fim de adaptá-los ao capital cultural das crianças menos favorecidas, aumentando suas eventuais chances de êxito escolar. A outra, de cunho mais fatalista, concebe a reprodução das desigualdades como um elemento estrutural do sistema escolar. Nessa perspectiva, a eventual superação dessa tendência ao fracasso se explicaria antes por algum tipo de resiliência do aluno do que pela fragilidade da estrutura de reprodução.

Assim, embora as autoproclamadas pedagogias críticas rompam com a visão organicista que animou a criação da escola republicana, com ela partilham dois pressupostos fundamentais: (1) emancipação e igualdade seriam objetivos só alcançáveis ao final de uma longa jornada e (2) resultantes da universalização da transmissão de um saber. Tanto na versão organicista como na histórico-crítica, o ponto de partida é o mesmo: a conviç̧ão da desigualdade. Se na primeira esta resulta da diferença entre dons e méritos pessoais, na segunda ele procederia de uma alegada incompatibilidade entre o legado (ou capital) cultural das crianças das classes trabalhadoras e a cultura escolar, vinculada aos habitus dos segmentos dominantes. Ademais, acrescenta Rancière (2002, tradução nossa), ambas padecem de mais um equívoco comum: não se dão conta de que "a distribuição de conhecimento, em si mesma, não implica consequências igualitárias em relação à ordem social". Em síntese, a despeito do antagonismo entre as respectivas visões de sociedade, ambas assumem a igualdade como fruto de uma longa jornada cujas veredas só alguns conhecem. E, ao assim fazerem, reiteram o caráter desigual de uma ordem social em que alguns - os sociólogos ou os professores - sabem não só da ignorância dos outros, como dos meios de superá-la.

Já em Jacotot, o mestre atesta seu compromisso com a emancipação intelectual e com a igualdade precisamente ao renunciar ao lugar que the foi preestabelecido pela ordem social: o daquele que, por saber da ignorância do outro, 


\section{Eithrapẫ}

ISSN: 1984-6444 | http://dx.doi.org/10.5902/1984644445306

\section{Considerações finais}

Nesta breve exposição acerca das diferentes formas pelas quais os discursos educacionais concebem e operacionalizam o princípio da igualdade, procurei demonstrar que, a despeito da adesão ao mesmo princípio, cada uma das correntes aqui abordadas possui perspectivas e pressupostos teóricos próprios, o que as torna não simplesmente distintas, mas irredutíveis e alternativas entre si. Contudo, se no plano do equacionamento teórico-conceitual essas correntes se confrontam e excluem, nas práticas cotidianas elas acabam por se amalgamar, ainda que não sem conflitos ou tensões. Por essa razão é plausível imaginar que uma instituição e seus agentes venham, por exemplo, a se comprometer com medidas de aperfeiçoamento da igualdade de oportunidades - como a implantação de políticas de ação afirmativa - e, simultaneamente, tomem como diretriz o desvelamento de lutas político-ideológicas relativas às escolhas curriculares. Ou, ainda, que procurem criar condições de possibilidade para experiências de verificação da igualdade na concretude de suas ações presentes. Não se trata, pois, de escolher um curso de ação a partir de uma filiação teórica, mas, antes, de lidar com limites e condicionantes do real.

Essa discrepância entre a radicalidade alternativa das diferentes posições teórico-conceituais e sua articulação mista e heterodoxa no campo das práticas cotidianas não deve ser interpretada como um desajuste entre teoria e prática, como sói acontecer. Ela, antes, deriva da peculiaridade de cada um desses domínios, de suas características e desafios. Em certo sentido, a irredutibilidade das perspectivas teóricas - que inviabiliza sua fusão em um todo abrangente - parece ser a própria condição de possibilidade do estabelecimento de distinções e da explicitação de pressupostos que desvelam a natureza dos problemas analisados. Por outro lado, é preciso reconhecer que não faz sentido, no plano das práticas e iniciativas institucionais, zelar por qualquer sorte de ortodoxia teórica supostamente capaz de obliterar a pluralidade e a diversidade como marcas de um projeto democrático de educação. Entre outras razões, porque o confronto inerente à diversidade de práticas e concepções é, em si mesmo, um compromisso com o sentido democrático 


\section{Autharão}

ISSN: 1984-6444 | http://dx.doi.org/10.5902/1984644445306

e republicano da educação. Não se trata, pois, de lutar pela adoção de uma perspectiva homogênea capaz de guiar as ações educativas, mas sim de fomentar o respeito à pluralidade de concepções como elemento constitutivo do ethos escolar.

Mas creio ser preciso ainda reconhecer que as maiores dificuldades que enfrentamos nesse desafio não residem nos inevitáveis conflitos das teorias entre si, nem naqueles derivados de sua apropriação heterodoxa nas práticas cotidianas. Elas, antes, residem na persistência de uma atitude - ou crença - que se encontra profundamente enraizada em nossa constituição histórica como Estado nacional. Tendo sido o Brasil o último país moderno a abolir a escravidão, a desigualdade se erigiu como uma ordem social duradoura e, muitas vezes, concebida como natural por uma parcela considerável de seus cidadãos, o que inclui, evidentemente, professores e professoras. Ora, no início destas reflexões evocamos Montesquieu (1996, p. 46) para alertar que, assim como "temos o poder de transmitir nossos conhecimentos a nossos filhos; temos o poder ainda maior de transmitir-lhes nossas paixões", que tanto podem ser o temor aos tiranos quanto o amor à igualdade ou o ardor pela distinção que marca a adesão à crença na desigualdade.

Cabe aqui, pois, uma breve reflexão sobre as formas pelas quais uma geração transmite ${ }^{3}$ - e não apenas comunica - seus princípios, paixões e crenças políticas àqueles que a sucederão. Se conhecimentos e técnicas são, em geral, veiculados por meio de enunciados e instruções práticas, o mesmo não ocorre com paixões e princípios políticos. Estes são transmitidos entre as gerações sobretudo por meio de práticas e exemplos; por palavras e gestos que têm o poder de encarnálos em atos passíveis de serem vistos, ouvidos e vividos - portanto, verificados - no presente. Isso porque se trata, neste caso, não da comunicação de um enunciado tido por verdadeiro ou proclamado como desejável, mas antes da transmissão de uma herança viva. Como nos alerta Michael Oakeshott (1989, p. 62, tradução nossa), essa herança viva de virtudes, paixões e princípios "só pode ser transmitida por um professor que verdadeiramente a valorize por si mesma, e que não se limite a recitá-la... [pois] não é o grito, mas o voo do pato silvestre o que faz com que o bando o siga". 


\section{usm Elllbap̧a}

ISSN: 1984-6444 | http://dx.doi.org/10.5902/1984644445306

Nesse sentido, o reconhecimento da solidez e da persistência histórica da crença na desigualdade em nossas formas de ver, pensar e agir política e socialmente não nos exime da luta incessante pelo cultivo de práticas de igualdade como forma mais efetiva de sua transmissão no âmbito das instituições escolares. Ao contrário, ele reforça sua urgência e complexidade e nos desafia a criar formas de atestação da igualdade tanto nas práticas pedagógicas como nas relações dos docentes entre si e com as instituições em que trabalham. Não se trata de suprimir a assimetria das responsabilidades entre docentes e discentes, mas de, a partir dela, encarar o paradoxo que dá sentido ao ofício de ser professor: comprometer-se com a verificação da igualdade em um mundo de desigualdades.

Trata-se, por fim, de reconhecer que a experiência escolar não pode ser reduzida a um instrumento - de resto, mais ou menos eficaz - de redução de desigualdades que the são exteriores, embora tenha o potencial de se erigir como uma experiência viva de verificação da igualdade como potencialidade do presente. Não é outro, como afirma Rancière, o próprio sentido político da democratização da escola republicana:

\footnotetext{
A escola não toma a igualdade como um objetivo, para o qual ela seria um meio. Ela não iguala por seu conteúdo - pelos conhecimentos com seus supostos efeitos de redistribuição social - mas por sua forma. A escola pública democrática já é redistribuição: ela subtrai do mundo desigual da produção uma parte de suas riquezas, para dedicá-la ao luxo que representa a constituição de um espaço-tempo igualitário. Se a escola muda a condição social dos alunos, é principalmente porque ela os faz participar de seu espaço-tempo igualitário, separado das exigências do trabalho. A banalização da forma escolar, ao identificar o tempo social da escola com o tempo natural de amadurecimento das crianças, mascara esta ruptura simbólica fundamental: o tempo livre [skholé] tornou-se parte do tempo da existência trabalhadora. (RANCIÈRE, 1988, tradução nossa).
}

Resistir a essa banalização, que concebe a escola a partir de uma lógica instrumental, pode ser uma forma singela de afirmar cotidianamente que aquilo que outrora foi um privilégio dos estamentos aristocráticos - o gozo de um tempo e um espaço de formação livres dos constrangimentos da ordem desigual da produção e do consumo - pode ser, aqui e agora, afirmado como um efetivo direito de todos. O direito à literatura, ao teatro, à filosofia, à matemática, às práticas corporais. $\mathrm{O}$ direito 


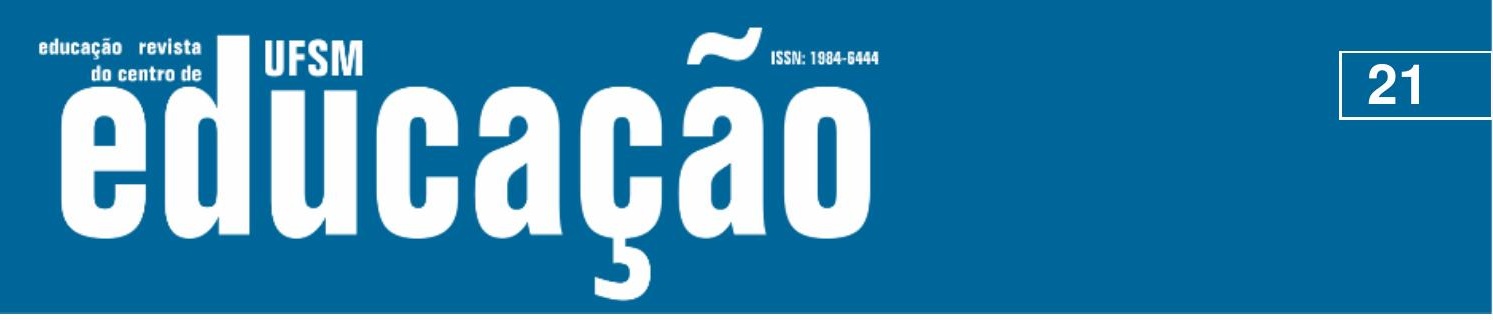

ISSN: 1984-6444 | http://dx.doi.org/10.5902/1984644445306

de cada criança adicionar, à sua dimensão privada de filho, a dimensão pública de ser um aluno, igual a todos os demais. O direito de fazer amigos fora de seu círculo familiar, de escolher mestres, de experimentar novos papéis. Direitos que não se justificam pelos seus supostos efeitos futuros na ordem social, mas pelo quanto o seu gozo no presente atesta a possibilidade da igualdade.

\section{Referências}

ARENDT, Hannah. Between the past and the future. New York: Penguin, 1996.

BOURDIEU, Pierre; PASSERON, Jean-Claude. Os herdeiros: os estudantes e a cultura. Florianópolis: Editora da UFSC, 2017.

BRAYNER, Flávio. Para além da educação popular. Campinas: Mercado das Letras, 2018.

CERLETTI, Alejandro. Repeticion, novedad y sujeto em la educación. Buenos Aires: Del Estante, 2008.

DUBET, François. L'Ecole des chances: Qu'est-ce qu'une école juste?. Paris: Seuil, 2004.

DURKHEIM, Émile. Educação e Sociologia. São Paulo: Melhoramentos, 1965.

GIROUX, Henry. Os professores como intelectuais. Porto Alegre: Artmed, 1997.

MONTESQUIEU, Charles. O espírito da Leis. São Paulo: Martins Fontes, 1996.

OAKESHOTT, Michael. Teaching and learning. In: OAKESHOTT, Michael. The voice of liberal learning. New Haven: Yale University Press, 1989. p. 43-62.

PLATÃO. A República. Belém: UFPA, 2000.

RANCIÈRE, Jacques. Aux bords du politique. Paris: Folio, 2003. (Edição portuguesa: RANCIĖRE, Jacques. Nas margens do político. Lisboa: KKYM, 2014.).

RANCIÈRE, Jacques. École, production, égalité. Paris: Horlieu, 1988. Disponível em: http://horlieu-editions.com/textes-en-ligne/politique/ranciere-ecole-productionegalite.pdf. Acesso em: 15 mar. 2019.

RANCIĖRE, Jacques. Le maître ignorant. Paris: Fayard, 1987. (Edição brasileira: RANCIÈRE, Jacques. O mestre ignorante. Tradução de Lilian do Vale. Belo Horizonte: Autêntica, 2011.) 


\section{N

ISSN: 1984-6444 | http://dx.doi.org/10.5902/1984644445306

RANCIÈRE, Jacques. O desentendimento. São Paulo: Editora 34, 2018.

RANCIÈRE, Jacques. Sur le maître ignorant. Conferência pronunciada na UERJ. Rio de Janeiro, 2002. Disponível em: https://www.multitudes.net/Sur-Le-Maitreignorant-2/. Acesso em: 03 abr. 2020.

RIBEIRO, Renato. Apresentação. In: MONTESQUIEU, Charles. O espírito da Leis. São Paulo: Martins Fontes, 1996.

SAVIANI, Demerval. Pedagogia histórico-crítica: primeiras aproximações. Campinas: Autores Associados, 2003.

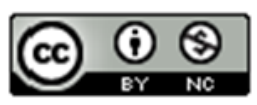

This work is licensed under a Creative Commons Attribution-NonCommercial 4.0 International (CC BY-NC 4.0)

\section{Notas}

\footnotetext{
1 O título faz uma óbvia alusão à conhecida passagem da obra O Romanceiro da Inconfidência, de Cecília Meireles: "Liberdade é uma palavra que o sonho humano alimenta, não há ninguém que explique e ninguém que não entenda".

2 Em O desentendimento Rancière (2018) alude à clássica distinção aristotélica entre phoné - a capacidade de comunicação imediata de diversos animais - e logos - discurso, linguagem, razão que faz do homem um ser político. Ser dotado de linguagem é ser inteligente; é conferir inteligibilidade à experiência.

${ }^{3}$ A noção de transmissão é aqui tomada em seu sentido estrito: uma comunicação eminentemente humana porque opera na dimensão histórica. Muitas espécies são capazes de comunicar algo no presente imediato, mas só os humanos legam uma herança cultural que se estende no tempo.
} 